\title{
Generation of deformation-induced martensite when cryogenic turning various batches of the metastable austenitic steel AISI 347
}

\author{
Benjamin Kirsch ${ }^{1} \cdot$ Hendrik Hotz ${ }^{1} \cdot$ Ralf Müller $^{2} \cdot$ Steven Becker ${ }^{2} \cdot$ Annika Boemke $^{3} \cdot$ Marek Smaga $^{3} \cdot$ Tilmann Beck $^{3} \cdot$ \\ Jan C. Aurich ${ }^{1}$
}

Received: 10 October 2018 / Accepted: 20 December 2018 / Published online: 17 January 2019

(C) The Author(s) 2019

\begin{abstract}
Cryogenic turning of metastable austenitic steels allows for a surface layer hardening integrated into the machining process, which renders a separate hardening process obsolete. This surface layer hardening is the result of a superposition of strain hardening mechanisms and deformation-induced phase transformation from austenite to martensite. The activation energy required for the latter depends on the chemical composition of the metastable austenitic steel. It can hence be expected that the austenitic stability of the workpiece material varies depending on the batch and that differences in the metallurgical surface layer properties and thus also in the microhardness result after cryogenic turning. Therefore, in this paper, various batches of the metastable austenitic steel AISI 347 were turned utilizing cryogenic cooling with the same machining parameters. The thermomechanical load during the experiments was characterized and the resulting subsurface properties were investigated. The content of deformation-induced $\alpha^{\prime}$-martensite was quantified via magnetic sensor measurements and the distribution was examined using optical micrographs of etched cross-sections. It was found that similar amounts of deformation-induced $\alpha^{\prime}$-martensite were generated in the workpiece surface layer for all batches examined. Furthermore, the workpieces were analyzed with regard to the maximal hardness increase and the hardness penetration depth based on microhardness measurements. A significant surface layer hardening was achieved for all batches. This shows that surface layer hardening integrated in the manufacturing process is possible regardless of batch-dependent differences in the chemical composition and thus varying austenite stability of the metastable austenitic steel.
\end{abstract}

Keywords Surface layer hardening $\cdot$ Cryogenic turning $\cdot$ Metastable austenitic steel $\cdot$ Deformation-induced phase transformation

\section{Introduction}

The surface layer properties of a component directly influence its operational behavior [1]. Component surfaces that are exposed to high tribological loads, such as shaft counter surfaces for radial shaft seals, must have high hardness in the

Benjamin Kirsch

benjamin.kirsch@mv.uni-kl.de

https://www.fbk-kl.de

$1 \quad$ Institute for Manufacturing Technology and Production Systems, University of Kaiserslautern, 67663 Kaiserslautern, Germany

2 Institute of Applied Mechanics, University of Kaiserslautern, 67663 Kaiserslautern, Germany

3 Institute of Materials Science and Engineering, University of Kaiserslautern, 67663 Kaiserslautern, Germany surface layer and at the same time a sufficient bulk toughness to guarantee their functionality [2]. For non-brittle materials like stainless austenitic steel, a high hardness in the workpiece surface layer also results in a longer service life of cyclically stressed components, because the crack initiation is hampered and the crack propagation rate is reduced [3-5]. Usually, workpieces are post-processed after machining by a subsequent heat treatment or a mechanical hardening process in order to increase the hardness of the workpiece surface layer. Specifically, workpieces made of austenitic stainless steel are usually mechanically hardened by deep rolling, hammering or shot peening $[6,7]$. These post-treatment processes plastically deform the workpiece surface layer and increase the hardness in the near-surface area by superimposing different hardening mechanisms [8]. The increase in hardness results from grain refinement, the formation of twin grain boundaries and an increased dislocation density 
$[9,10]$. However, the additional post-treatment process leads to prolonged process chains and thus also to an increase in production costs.

In recent years, a cryogenic turning process has been developed to harden the workpiece surface layer of metastable austenitic steels already during the machining process and thus to render the additional post-treatment process obsolete [11]. For a large number of materials, a hardness increase in the workpiece surface layer was already observed after cryogenic machining, which results from the hardening mechanisms mentioned above [12]. When turning metastable austenitic steels under cryogenic cooling, a phase transformation from $\gamma$-austenite into $\alpha^{\prime}$ - and $\varepsilon$-martensite occurs in the workpiece surface layer [11]. It is therefore possible to superimpose the strain hardening mechanisms with the deformation-induced martensite formation, thus enabling more effective surface hardening. The hardened surface layer of cryogenically turned workpieces results in a higher wear resistance [13] and fatigue resistance [14] and thus improves the components application behavior. Deformation-induced martensite generation and strain hardening mechanisms are both favored by high passive forces and low workpiece temperatures during the turning process [15]. By adapting the $\mathrm{CO}_{2}$ mass flow rate, nozzle position, machining parameters and cutting edge geometry, the thermomechanical load in the turning process can be controlled. This also enables the control of the martensite content in the workpiece surface layer as well as the hardness [15-19]. However, the materialspecific properties of the workpiece and its effect on the resulting martensite content and subsurface properties after cryogenic turning has not been researched yet. The chemical composition and grain size have a significant effect on the austenite stability [20,21]. The thermodynamic stability of the austenitic phase increases in particular with increasing proportions of the alloying elements nickel (Ni), chromium $(\mathrm{Cr})$, manganese (Mn), molybdenum (Mo), silicon ( $\mathrm{Si}$ ) and especially carbon $(\mathrm{C})$ and nitrogen $(\mathrm{N})[22,23]$. Due to the effect of the alloying elements on the austenite stability, differences in the resulting $\alpha^{\prime}$-martensite content after cryogenic turning are to be expected when turning different batches. In this paper, different batches of the metastable austenitic steel AISI 347 were turned under identical conditions to investigate the influence of the chemical composition on the resulting subsurface properties.

\section{Phase transformation of metastable austenitic steels and investigated materials}

In metastable austenitic stainless steels, a phase transformation from paramagnetic fcc $\gamma$-austenite to ferromagnetic bcc $\alpha^{\prime}$-martensite occurs due to deformation or cooling. The thermodynamical background of this phase transformation is schematically shown in Fig. 1.

At the temperature $\mathrm{T}_{0} \gamma$-austenite and $\alpha^{\prime}$-martensite are in thermodynamic equilibrium as their free energies have the same values. Below $\mathrm{T}_{0}$ the phase transformation from $\gamma$-austenite to $\alpha^{\prime}$-martensite is possible, but occurs only, if a minimum difference of free energy $\Delta \mathrm{G}_{\min }^{\alpha^{\prime}}$ is provided. At the martensite start temperature $\mathrm{M}_{\mathrm{s}}$ the difference in free energy $\Delta \mathrm{G}_{\min }^{\alpha^{\prime}}$ due to the temperature decrease is sufficient to induce the transformation (energy is provided by $\Delta \mathrm{G}_{\text {chem }}$ ). Between $\mathrm{M}_{\mathrm{s}}$ and $\mathrm{T}_{0}$, a phase transformation can only occur if an additional amount of energy difference $\Delta \mathrm{G}_{\text {mech }}$ is provided by deformation; the sum of $\Delta \mathrm{G}_{\text {mech }}$ and $\Delta \mathrm{G}_{\text {chem }}$ has to reach the level of $\Delta \mathrm{G}_{\min }^{\alpha^{\prime}}$

The $M_{s}$ and $M_{d}$ temperatures can therefore be used as indicators for characterizing the austenite stability (see Fig. 1). Since the $M_{d}$-temperature is difficult to determine experimentally, the $\mathrm{M}_{\mathrm{d} 30}$-temperature was introduced by Angel et al. [23]. The $\mathrm{M}_{\mathrm{d} 30}$-temperature is the value where $50 \%$ martensite is formed when $30 \%$ plastic strain is applied. The $\mathrm{M}_{\mathrm{s}}$-temperature is primarily used to estimate the austenite stability during the purely thermally induced phase transformation, whereas the $\mathrm{M}_{\mathrm{d} 30^{-}}$temperature is a proven indicator for the austenite stability with respect to the deformation-induced phase transformation. Based on the chemical compostion, the $\mathrm{M}_{\mathrm{s}}$ temperature according to Eichelmann [22] and the $\mathrm{M}_{\mathrm{d} 30^{-}}$-temperature according to Angel [23] can be calculated by the following equations:

$$
\begin{aligned}
\mathrm{M}_{\mathrm{s}, \text { Eichelmann }}= & 1350-1665(\mathrm{C}+\mathrm{N})-28 \mathrm{Si} \\
& -33 \mathrm{Mn}-42 \mathrm{Cr}-61 \mathrm{Ni} \text { in }{ }^{\circ} \mathrm{C} \\
\mathrm{M}_{\mathrm{d} 30, \text { Angel }}= & 413-462(\mathrm{C}+\mathrm{N})-13.7 \mathrm{Cr}-9.5 \mathrm{Ni} \\
- & 8.1 \mathrm{Mn}-18.5 \mathrm{Mo}-9.2 \mathrm{Si} \text { in }{ }^{\circ} \mathrm{C}
\end{aligned}
$$

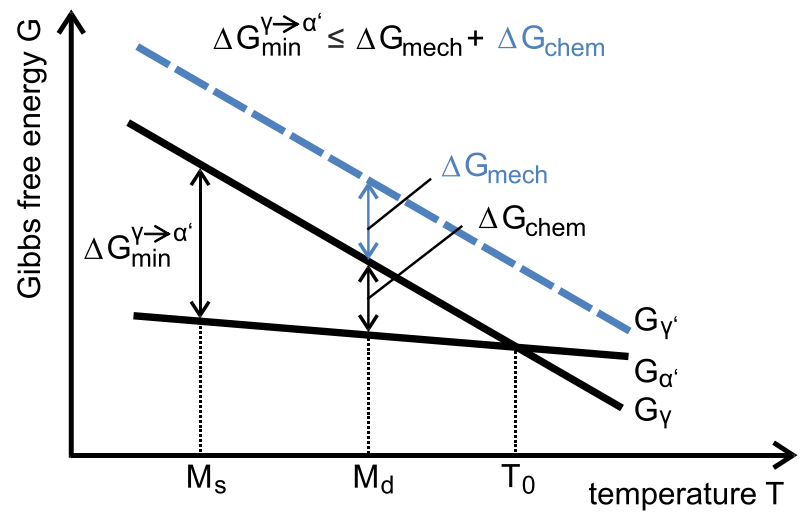

Fig. 1 Correlation between Gibbs free energy $G$ and temperature $T$ from [15] according to [24] 
Table 1 Chemical composition of 5 batches of AISI 347 in wt $\%$

\begin{tabular}{llllllllll}
\hline & $\mathrm{C}$ & $\mathrm{Cr}$ & \multicolumn{1}{c}{$\mathrm{Ni}$} & $\mathrm{N}$ & $\mathrm{Nb}$ & $\mathrm{Mn}$ & $\mathrm{Mo}$ & $\mathrm{Si}$ & $\mathrm{Cu}$ \\
\hline B1 & 0.024 & 17.29 & 9.25 & 0.019 & 0.41 & 1.55 & 0.19 & 0.63 & 0.21 \\
$\mathrm{~B} 2$ & 0.021 & 17.19 & 9.44 & 0.022 & 0.38 & 1.55 & 0.23 & 0.59 & 0.11 \\
B3 & 0.014 & 18.31 & 10.06 & 0.025 & 0.38 & 0.65 & 0.06 & 0.47 & 0.15 \\
B4 & 0.026 & 17.28 & 9.15 & 0.017 & 0.35 & 1.56 & 0.23 & 0.64 & 0.15 \\
B5 & 0.031 & 18.04 & 10.11 & 0.027 & 0.36 & 0.65 & 0.042 & 0.54 & 0.13 \\
\hline
\end{tabular}

\begin{tabular}{lcllll}
\hline & $\mathrm{M}_{\mathrm{s}, \text { Eichelmann }}$ in ${ }^{\circ} \mathrm{C}$ & $\begin{array}{l}\mathrm{M}_{\mathrm{d} 30, \text { Angel }} \\
\text { in }{ }^{\circ} \mathrm{C}\end{array}$ & $\begin{array}{l}\text { Average grain } \\
\text { diameter in } \mu \mathrm{m}\end{array}$ & $\begin{array}{l}\text { Content of } \alpha^{\prime} \text {-martensite after } \\
\text { workpiece preparation in vol\% }\end{array}$ & $\begin{array}{l}\text { Microhard- } \\
\text { ness in } \\
\text { HV0.01 }\end{array}$ \\
\hline B1 & -81 & 46 & $17 \pm 1.5$ & $1 \pm 0.2$ & $189 \pm 13.6$ \\
B2 & -87 & 46 & $17 \pm 0.1$ & $0 \pm 0$ & $176 \pm 8.9$ \\
B3 & -133 & 38 & $18 \pm 1$ & $1.4 \pm 0.2$ & $177 \pm 10.2$ \\
B4 & -75 & 47 & $15 \pm 0.4$ & $0.2 \pm 0.2$ & $182 \pm 15.7$ \\
B5 & -158 & 32 & $16 \pm 0.9$ & $1.3 \pm 0.2$ & $178 \pm 6.9$ \\
\hline
\end{tabular}

Table 2 Metallurgical and mechanical properties of the batches of AISI 347
Table 3 Tool geometry and cutting parameters

Tool geometry (CNMA 120416 T02020)

\begin{tabular}{ll}
\hline Corner radius: $1.6 \mathrm{~mm}$ & Clearance angle: $6^{\circ}$ \\
Rake angle: $-6^{\circ}$ & Tool cutting edge inclination: $-6^{\circ}$ \\
Chamfer angle: $20^{\circ}$ & Projected chamfer width: $0.2 \mathrm{~mm}$ \\
Coating: multilayer (TiN/TiCN/ $\mathrm{Al}_{2} \mathrm{O}_{3}$ ) \\
\hline Cutting parameters \\
\hline Cutting speed & $30 \mathrm{~m} / \mathrm{min}$ \\
Depth of cut & $0.2 \mathrm{~mm}$ \\
Feed rate & $0.35 \mathrm{~mm} / \mathrm{rev}$ \\
\hline
\end{tabular}

area during pre-processing (dry cutting to the initial diameter of $14.4 \mathrm{~mm}$; see Table 2). However, its depth is much smaller than the depth of cut applied in the subsequent cryogenic turning experiments. Hence, this thin layer is completely removed and does not influence the martensite formation of the actual cut. To ensure sufficient statistics, four workpieces were turned out of each batch (B1-B5). A new insert was used for each workpiece in order to minimize the influence of wear. The tool geometry and cutting parameters were kept constant. The machining parameters, taken from previous investigations, are listed in Table 3.

To maintain the necessary low temperatures in order to achieve phase transformation, a $\mathrm{CO}_{2}$ solid-gas-mixture was applied as coolant via two external nozzles at approx. $-78{ }^{\circ} \mathrm{C}$ [12]. One nozzle supplied the $\mathrm{CO}_{2}$ from flank face direction directly into the contact zone. The second nozzle served for precooling of the workpiece from rake face direction (see Fig. 2). The mass flow rate per nozzle was $1.75 \mathrm{~kg} / \mathrm{min}$. To ensure uniform test conditions, the $\mathrm{CO}_{2}$
The workpieces were turned on a CNC lathe with a feed travel of $18 \mathrm{~mm}$ to a final diameter of $14 \mathrm{~mm}$. A thin layer with low martensite content is formed in the near surface 
cooling system was activated automatically with the NC program.

The workpiece temperature was determined with an infrared thermography system located outside of the CNC lathe. As the contact zone is not accesible for thermographic measurements, the workpiece surface temperature was measured after a 3/4 rotation of the workpiece in order to evaluate and compare the thermal load for the different batches. The process forces were recorded with a piezoelectric three-component dynamometer.

The phase transformation from $\gamma$-austenite into $\alpha^{\prime}$-martensite results in a change of the magnetic permeability since $\alpha^{\prime}$-martensite is ferromagnetic, while $\gamma$-austenite is paramagnetic. Therefore, it was possible to evaluate the content of the deformation-induced $\alpha^{\prime}$-martensite generated in the turning process nondestructively. This was done by means of a magnetic sensor, type Ferritscope ${ }^{\mathrm{TM}}$, which detects ferromagnetic phase fractions up to a depth of approx. $3 \mathrm{~mm}$ below the workpiece surface, see [15]. However, $\varepsilon$-martensite cannot be detected by the magnetic sensor, as it has paramagnetic properties like austenite. Furthermore, only the integral $\alpha^{\prime}$-martensite content can be determined with the Ferritscope ${ }^{\mathrm{TM}}$ and no statements on the exact martensite distribution can be made. However, it is an easy and reliable method to detect the phase transformation as an integral value and hence to evaluate metastabilty of the different batches. A multiplication factor of 1.7 was used to convert the feritscope reading (FE-\%) into the $\alpha^{\prime}$-martensite content according to [31].

Microhardness measurements were carried out with a vickers indenter to determine the hardness profiles in the workpiece subsurface. Indentations were carried out from 20 to $400 \mu \mathrm{m}$ below the surface at intervals of $10 \mu \mathrm{m}$ with a load force of $100 \mathrm{mN}$ (HV 0.01) and a loading time of $10 \mathrm{~s}$. Three microhardness profiles of one respective workpiece of each batch were determined and averaged.

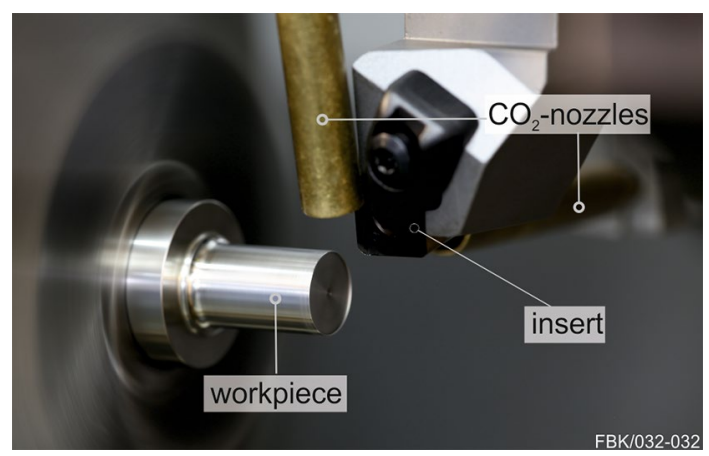

Fig. 2 Experimental setup for cryogenic turning

\section{Results}

\subsection{Thermomechanical load}

The mean values of the feed force $F_{f}$, passive force $F_{p}$ and cutting force $F_{c}$ are shown in Fig. 3. As the cutting depth $\mathrm{a}_{\mathrm{p}}=0.2 \mathrm{~mm}$ was significantly smaller than the cutting edge radius $r_{\beta}=1.6 \mathrm{~mm}$, the workpiece material was exclusivly removed by the corner of the insert. The low depths of cut, in connection with the chamfer, resulted in an almost constant, negative effective rake angle in the entire cutting cross section, which led to high passive forces. This was intended, as high passive forces are essential for the generation of deformation-induced martensite in the workpiece subsurface regions.

The mean surface temperatures recorded during the turning experiments are shown in Fig. 4. The differences in chemical composition of the different batches had no significant influence on the thermomechanical loads. Since the process forces were similar for the different batches, the

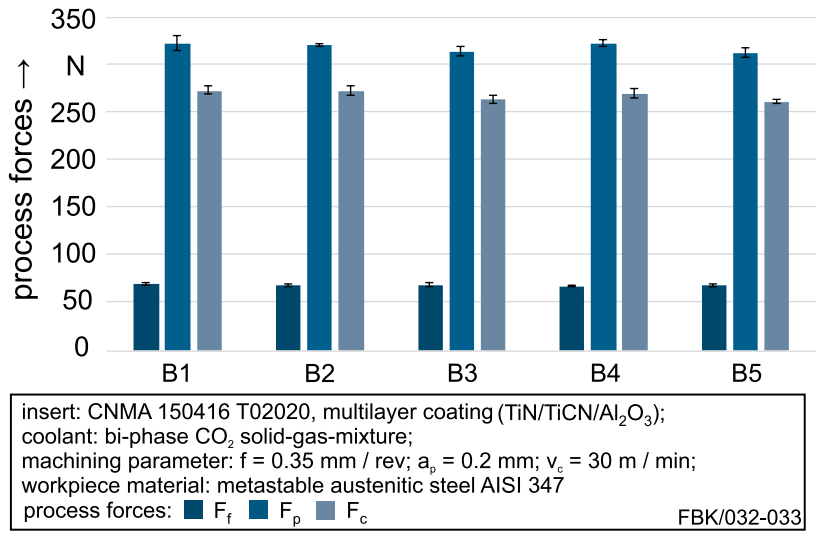

Fig. 3 Process forces

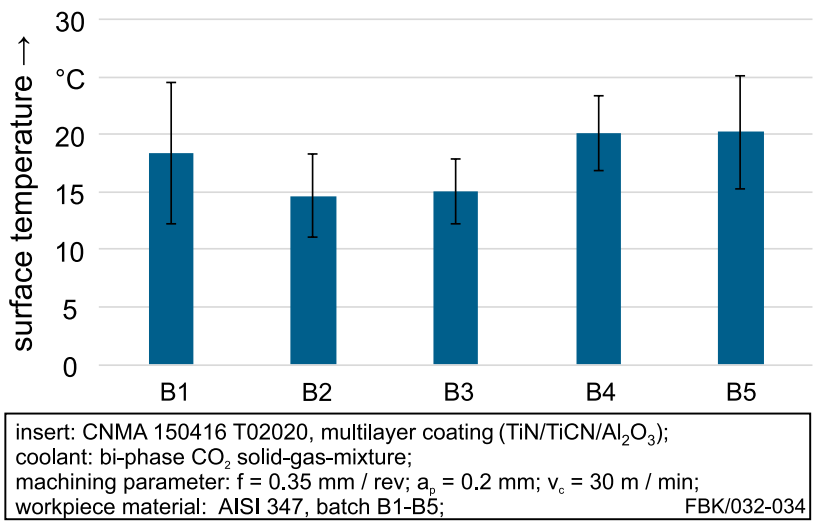

Fig. 4 Surface temperature 
heat generated in the nearly adiabatic primary shear zone and thus also the measured temperatures were similar as well and their differences where within the standard deviation. The temperature at the workpiece surface is approx. 20-30 ${ }^{\circ} \mathrm{C}$ lower than the $\mathrm{M}_{\mathrm{d} 30 \text {, Angel }}$-temperature and significantly higher $\left(90-180^{\circ} \mathrm{C}\right)$ than the $\mathrm{M}_{\mathrm{s}, \text { Eichelmann }}{ }^{- \text {temperature. }}$

\subsection{Deformation-induced $a^{\prime}$-martensite}

The integral contents of $\alpha^{\prime}$-martensite in the workpiece surface layer after cryogenic turning are shown in Fig. 5 as a function of the $\mathrm{M}_{\mathrm{d} 30 \text {,Angel }}$-temperature. Despite the differences in the chemical composition and the associated austenite stability, the magnitude of deformation-induced $\alpha^{\prime}$-martensite content of the batches B2-B5 was in the range of the standard deviation. Only batch B1 showed a slightly higher $\alpha^{\prime}$-martensite content. Since the chemical composition of B1 was similar to that of B2 and B4 (see Table 1), this difference in $\alpha^{\prime}$-martensite content cannot be attributed solely to the differences in the chemical composition.

Figure 6 exemplarily shows metallographic sections perpendicular through the surfaces of the cryogenically turned workpieces etched with Beraha II. The materials show

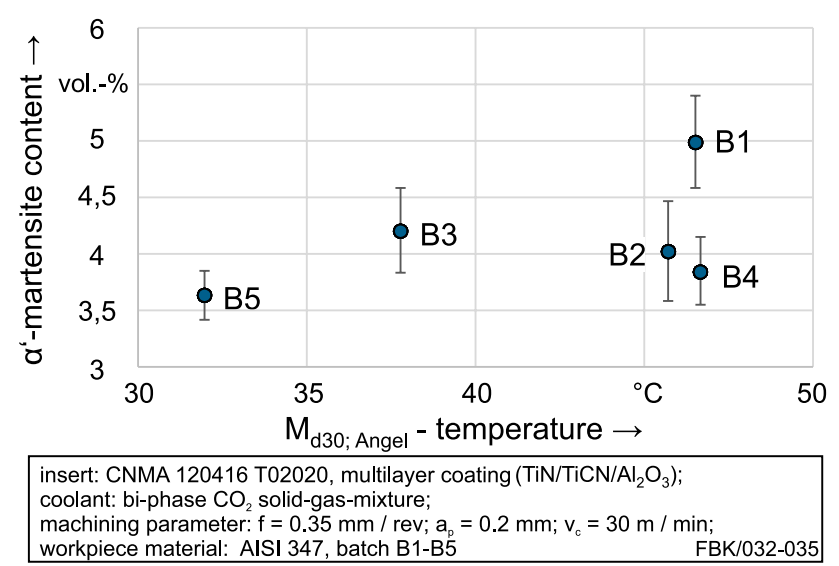

Fig. 5 Content of $\alpha^{\prime}$-martensite generated in cryogenic turning in relation to $\mathrm{M}_{\mathrm{d} 30, \text { Angel }^{-}}$-temperature calculated via Eq. 1 segregations due to their chemical inhomogenitiy. It can be seen that all batches have a martensitic needle structure in the surface layer colored in black on the right side of the images. Underneath this surface layer, an austenitic structure is visible.

\subsection{Microhardness}

The percentage standard deviation of the microhardness profiles was between $3.88 \%$ (B5) and $8.63 \%$ (B4). Regressions for the microhardness profiles were calculated on the basis of the gaussian distribution function, which are shown in Fig. 7. Depending on the batch, values between 0.94 (B1; B3) and 0.98 (B2) were calculated for the coefficient of determination.

Near the surface, this function first shows a progressive decrease, which changes into a degressive decrease in microhardness and then approaches the initial hardness $\mathrm{HV}_{0} 0.01$. The initial hardness $\mathrm{HV}_{0} 0.01$ was measured in the bulk material, which was not modified by the cryogenic turning process. The fitting parameters $a$ and $b$ of the regression were determined according to the method of least squares

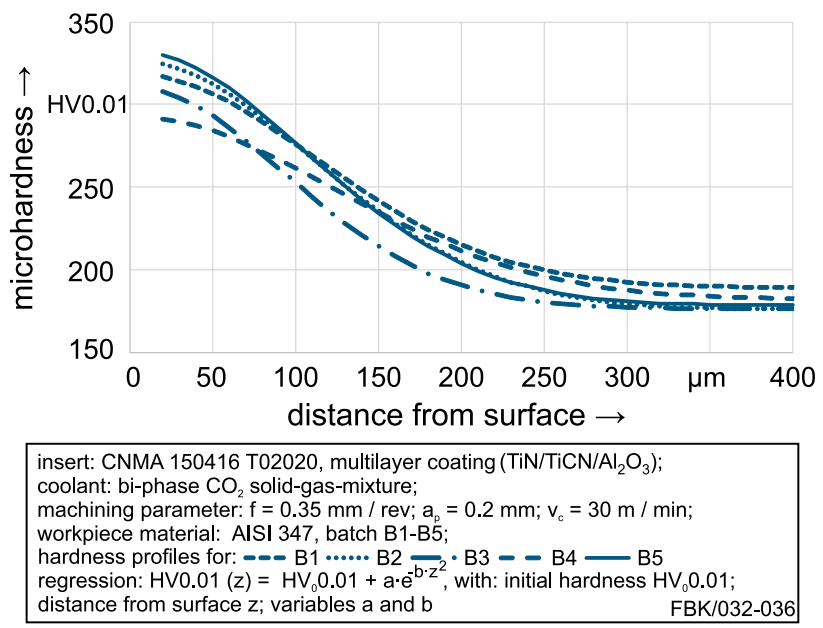

Fig. 7 Microhardness profiles
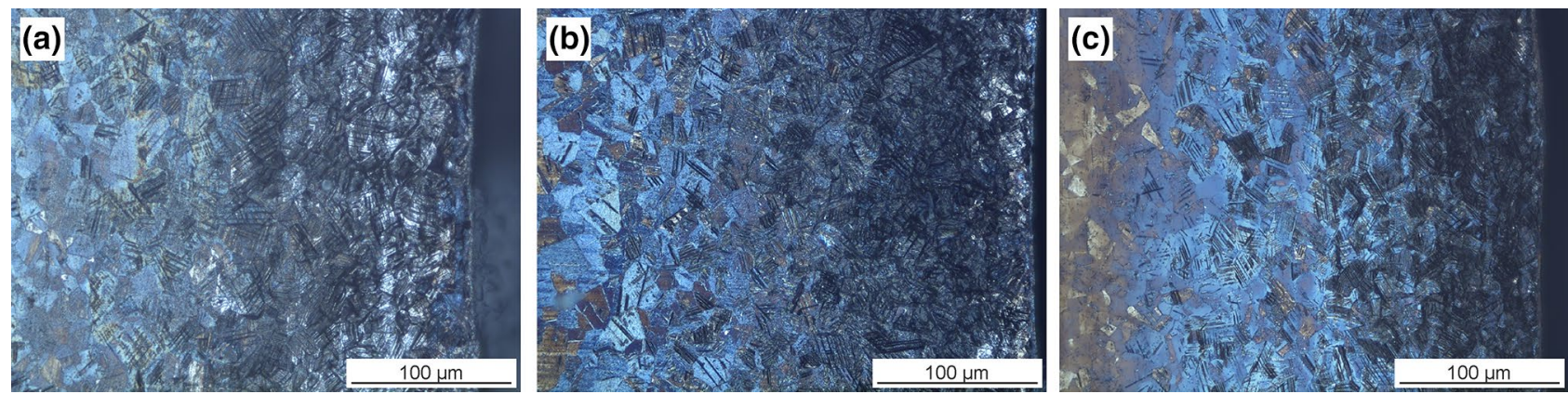

Fig. 6 Optical micrographs of B1 (a), B2 (b) and B4 (c) after cryogenic turning 
(see Table 4). Parameter $a$ describes the difference between the initial hardness $\mathrm{HV}_{0} 0.01$ and maximum hardness. The exponent $b$ determines the gradient of the function. In general, for otherwise constant fitting parameters, small values for $b$ imply a slow flattening of the function resulting in a high hardness penetration depth. The hardness penetration depth represents the threshold between the hardened subsurface and the unaffected base material. It was quantified as the distance from the surface in which the hardness corresponds to $120 \%$ of the initial hardness.

A significant increase in hardness was observed in the workpiece subsurface region of all five batches. For all experiments, the maximum hardness occurred immediately below the workpiece surface. In relation to the initial hardness of the individual batches, the increase in hardness was between $61 \%$ (B4) and $87 \%$ (B5). The hardness penetration depth was between $154 \mu \mathrm{m}$ (B3) and $209 \mu \mathrm{m}$ (B1). A distinct correlation between the increase in hardness as well as the hardness penetration depth and the $\alpha$ '-martensite generated in the cryogenic turning process could not be determined (see Fig. 8).

In recent experiments [18], a rise in maximum hardness and hardening depth was also observed when the $\alpha^{\prime}$-martensite content increased. In those experiments, the increase in the $\alpha^{\prime}$-martensite content was caused by an increase in passive force via an increase in feed and cutting edge radius. Thus, the plastic deformation in the workpiece subsurface increased and, in addition to the phase transformation, also favoured the strain hardening mechanisms. Note that these experiments were only carried out on one batch (B2), therefore the initial state of all workpieces was the same.

In the experiments presented in this paper, the influence of different hardening mechanisms can vary, depending on the initial material state and the respective changes of them during the turning process. Thus, it can be assumed, that the total increase in hardness in the subsurface region cannot be exclusively attributed to the formation of deformation-induced $\alpha^{\prime}$-martensite. Formation of $\varepsilon$-martensite and/ or stacking faults, as well as increased dislocation density, grain refinement and formation of twins also contribute to
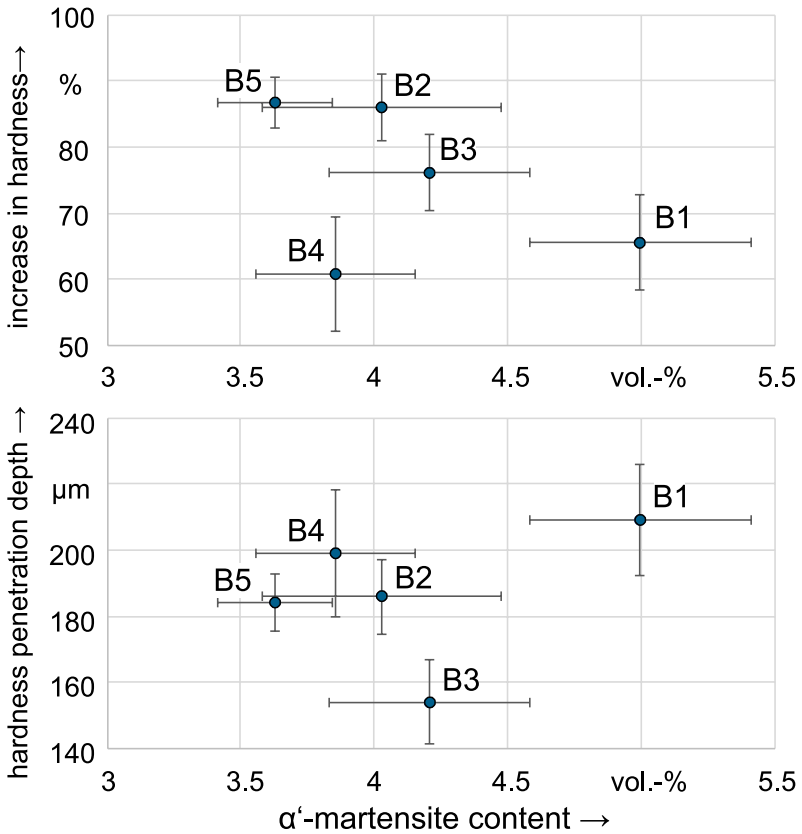

insert: CNMA 120416 T02020, multilayer coating ( $\left.\mathrm{TiN} / \mathrm{TiCN} / \mathrm{Al}_{2} \mathrm{O}_{3}\right)$ coolant: bi-phase $\mathrm{CO}_{2}$ solid-gas-mixture;

machining parameter: $f=0.35 \mathrm{~mm} / \mathrm{rev} ; a_{0}=0.2 \mathrm{~mm} ; v_{c}=30 \mathrm{~m} / \mathrm{min}$;

$\begin{array}{ll}\text { workpiece material: AISI 347, batch B1-B5; } & \text { FBK/032-037 }\end{array}$

Fig. 8 Correlation between mechanical properties of the workpiece surface layer and its $\alpha^{\prime}$-martensite content

hardening. To quantify these influences, the exact phase distribution of $\alpha^{\prime}$ - and $\varepsilon$-Martensite and other material defects would have to be detected e.g. via X-ray diffraction and high-resolution microscopy.

\section{Conclusions and outlook}

In this paper results of cryogenic turning experiments on five batches of the metastable austenitic steel AISI 347 are presented. Cryogenic turning was performed with the same process conditions (tools, coolant supply, process parameters), in order to examine the influence of chemical composition and, hence, metastability of the workpiece
Table 4 Fitting parameters for regression of microhardness profiles, values for uncertainty determination and resulting indicators for quantifying the subsurface hardening

\begin{tabular}{|c|c|c|c|c|c|c|c|}
\hline \multirow[t]{2}{*}{ Batch } & \multicolumn{3}{|c|}{ Fitting parameter } & \multicolumn{2}{|c|}{ Uncertainty } & \multicolumn{2}{|l|}{ Results } \\
\hline & $\mathrm{HV}_{0} 0.01$ & $a$ & $b$ & $\sigma(\%)$ & $\mathrm{R}^{2}$ & $\begin{array}{l}\text { Increase in hard- } \\
\text { ness }(\%)\end{array}$ & $\begin{array}{l}\text { Hardness pen- } \\
\text { etration depth } \\
(\mu \mathrm{m})\end{array}$ \\
\hline B1 & 189 & 130 & 40 & 7.18 & 0.94 & 66 & 209 \\
\hline B2 & 176 & 151 & 41.5 & 5.08 & 0.98 & 86 & 186 \\
\hline B3 & 177 & 134 & 56.5 & 5.74 & 0.94 & 76 & 154 \\
\hline B4 & 182 & 111 & 33 & 8.63 & 0.96 & 61 & 199 \\
\hline B5 & 178 & 155 & 45 & 3.88 & 0.96 & 87 & 184 \\
\hline
\end{tabular}


material on the resulting subsurface microstructure and properties. Although all batches met the ISO standard requirements for AISI 347 stainless steel, differences in their chemical composition resulted in different $\mathrm{M}_{\mathrm{s}, \text { Eichelmann }}{ }^{-}$and $\mathrm{M}_{\mathrm{d} 30 \text {,Angel }}$-temperatures.

In the experiments, no significant differences in process forces and temperatures were measured depending on the batch. After cryogenic turning, deformation-induced $\alpha^{\prime}$-martensite was detected in the workpieces of all investigated batches. The integral contents of $\alpha^{\prime}$-martensite were in a similar range for the various batches, varying from 3.6 to 5 vol.\%. When comparing the optical micrographs of the different batches, there were some minor differences in the martensite distribution. However, in all batches, the $\alpha^{\prime}$-martensite only occurred up to a depth of $250 \mu \mathrm{m}$ below the surface generated by cryogenic turning.

For all batches a pronounced surface layer hardening was observed after cryogenic turning, slightly varying in its magnitude among the batches. However, no distinct correlations between $\alpha^{\prime}$-martensite content and hardness increase or hardness penetration depth could be determined. Thus, the surface layer hardening during cryogenic turning cannot be exclusively traced back to the volume of $\alpha^{\prime}$-martensite generated.

Cryogenic turning proved to be suitable to realize a robust surface layer hardening integrated in the manufacturing process, even at a different austenite stability of the workpiece material. The quantification of the influence of phase distribution, grain refinement, dislocation density and residual stresses on the total increase in hardness and the hardness penetration depth via in-depth analyses is to be driven forward in the future. Furthermore, fatigue tests will be carried out on cryogenically turned specimen from different batches in order to investigate the correlation between the surface integrity and the fatigue behavior.

Acknowledgements The authors thank the German Research Foundation (DFG) for the support of the research within the DFG project CRC 926 "Microscale Morphology of Component Surfaces (MICOS)". Naming of specific manufacturers is done solely for the sake of completeness and does not necessarily imply an endorsement of the named companies nor that the products are necessarily the best for the purpose.

Open Access This article is distributed under the terms of the Creative Commons Attribution 4.0 International License (http://creativeco mmons.org/licenses/by/4.0/), which permits unrestricted use, distribution, and reproduction in any medium, provided you give appropriate credit to the original author(s) and the source, provide a link to the Creative Commons license, and indicate if changes were made.

\section{References}

1. Jawahir IS, Brinksmeier E, M'Saoubi R, Aspinwall DK, Outeiro JC, Meyer D, Umbrello D, Jayal AD (2011) Surface integrity in material removal processes: recent advances. CIRP Ann Manuf Technol 60:603-626

2. Jung S (2012) Beitrag zum Einfluss der Oberflächencharakteristik von Gegenlaufflächen auf das tribologische System RadialWellendichtung. Dissertation. University of Stuttgart

3. Bagherifard S, Slawik S, Fernández-Pariente I, Pauly C, Mücklich F, Guagliano M (2016) Nanoscale surface modification of AISI 316L stainless steel by severe shot peening. Mater Des 102:68-77

4. Boardman B (1990) Fatigue resistance of steels. ASM handbook: properties and selection: irons, steels and high-performance alloys. ASM International, Materials Park, pp 673-688

5. Mughrabi H, Donth B, Vetter G (1997) Low-temperature autofrettage: an improved technique to enhance the fatigue resistance of thick-walled tubes against pulsating internal pressure. Fatigue Fract Eng Mater Struct 20(4):595-604

6. Nikitin I, Scholtes B (2012) Deep rolling of austenitic steel AISI 304 at different temperatures. J Heat Treat Mater 3:188-194

7. Meyer D (2012) Cryogenic deep rolling—an energy based approach for enhanced cold surface hardening. CIRP Ann Manuf Technol 61(1):543-546

8. Garbrecht M (2006) Mechanisches Randschichthärten. Dissertation. Universität Bremen

9. Ambrosy F, Zanger F, Schulze V, Jawahir IS (2014) An experimental study of cryogenic machining on nanocrystalline surface layer generation. Proc CIRP 13:169-174

10. Gershteyn G, Shevchenko N, Diekamp M, Brosius A, Schaper M, Bach FW (2012) Features of austenitic steels' microstructure following plastic deformation. Materialwiss Werkstofftech 3:262-267

11. Aurich JC, Mayer P, Kirsch B, Eifler D, Smaga M, Skorupski R (2014) Characterization of deformation induced surface hardening during cryogenic turning of AISI 347 CIRP. Ann Manuf Technol 63(1):65-68

12. Jawahir IS, Attia H, Biermann D, Duflou J, Klocke F, Meyer D, Newman ST, Pusavec F, Putz M, Rech J, Schulze V, Umbrello D (2016) Cryogenic manufacturing processes. CIRP Ann Manuf Technol 65(2):713-736

13. Frölich D, Magyar B, Sauer B, Mayer P, Kirsch B, Aurich JC, Skorupski R, Smaga M, Beck T, Eifler D (2015) Investigation of wear resistance of dry and cryogenic turned metastable austenitic steel shafts and dry turned and ground carburized steel shafts in the radial shaft seal ring system. Wear 328-329:123-131

14. Smaga M, Skorupski R, Mayer P, Kirsch B, Aurich JC, Raid I, Seewig J, Man J, Eifler D, Beck T (2017) Influence of surface morphology on fatigue behavior of metastable austenitic stainless steel AISI 347 at ambient temperature and $300^{\circ} \mathrm{C}$. Proc Struct Integr 5:989-996

15. Mayer P, Skorupski R, Smaga M, Eifler D, Aurich JC (2014) Deformation induced surface hardening when turning metastable austenitic steel AISI 347 with different cryogenic cooling strategies. Proc CIRP 14:101-106

16. Mayer P, Kirsch B, Aurich JC (2014) Investigations on cryogenic turning to achieve surface hardening of metastable austenitic steel AISI 347. In: Advanced materials research 1018—proceedings of the WGP congress 2014-progress in production engineering pp 153-160

17. Becker S, Hotz H, Kirsch B, Aurich JC, von Harbou E, Müller R (2018) A finite element approach to calculate temperatures arising during cryogenic turning of metastable austenitic steel AISI 347. ASME J Manuf Sci Eng 140(10):101016-101016

18. Hotz H, Kirsch B, Gutwein S, Becker S, von Harbou E, Müller R, Aurich JC (2018) Kryogenes Drehen von X6CrNiNb18-10 - Einfluss des Schneidkantenradius auf Prozesskräfte und Prozessergebnisgrößen. wt Werkstattstechnik online 108(1-2):12-17

19. Hotz H, Kirsch B, Becker S, von Harbou E, Müller R, Aurich JC (2018) Improving the surface morphology of metastable 
austenitic steel AISI 347 in a two-step turning process. Proc CIRP 71:160-165

20. Becker H, Brandis H, Küppers W (1986) Zur Verfestigung instabil austenitischer nichtrostender Stähle und ihre Auswirkung auf das Umformverhalten von Feinblechen. Thyssen Edelstähle Technische Berichte 12(1):35-54

21. Nohara K, Yutaka O, Ohashi N (1977) Composition and grain size dependencies of strain-induced martensitic transformation in metastable austenitic stainless steels. Tetsu-to-Hagane 63(5):212-222

22. Eichelmann GC, Hull TC (1953) The effect of composition on the temperature of spontaneous transformation of austenite to martensite in 18-8 type stainless steel. Trans Am Soc Metals 45:77-104

23. Angel T (1954) Formation of martensite in austenitic stainless steels-effect of deformation, temperature, and composition. J Iron Steel Inst 177(1):165-174

24. Wayman CM, Bhadeshia HKDH (1996) Phase transformations, nondiffusive. Physical metallurgy, 4th edn. Elsevier, Amsterdam, pp 1507-1554
25. Monkmann FC, Cuff FB, Grant NJ (1957) Computation of Ms for stainless steels. Metal Progress 71:94-96

26. Pickering FB (1978) Physical metallurgy and the design of steels. Applied Science Publisher, London

27. Gladmann T, Hammond J, Marsh FW (1974) Austenitic stainless steels for cold forming. Sheet Metal Ind 51(5):219-239

28. Sjöberg IJ (1973) Influence of analysis on properties of stainless spring steel. Wire 23:155-158

29. Raman GS, Padmanabhan KA (1994) Influence of martensite formation and grain size on room temperature low cycle fatigue behavior of AISI 304LN austenitic stainless steel. Mater Sci Technol 10:614-620

30. Shrinivas V, Varma SK, Murr LE (1995) Deformation-Induced martensitic characteristics in 304 stainless and 316 stainless steels during room temperature rolling. Metal Mat Trans A 26:661-671

31. Talonen J, Nenonen P, Pape G, Hänninen H (2005) Effect of strain rate on the strain-induced $\gamma \rightarrow \alpha^{\prime}$-martensite transformation and mechanical properties of austenitic stainless steels. Metal Mat Trans A 36:421-432 